\title{
FORMAÇÃO DE PROFESSORES: TENSÃO ENTRE DISCURSOS, POLÍTICAS, TEORIAS E PRÁTICAS*
}

\author{
Cleoni Maria Barbosa Fernandes; \\ Maria Isabel da Cunha, \\ da Universidade Federal de Rio Grande do Sul - UFRGS.
}

\begin{abstract}
Resumo: Os questionamentos sobre a formação de professores provocam inquietações para a produção de sentidos que permita uma compreensão e intervenção nos processos formativos. São processos impregnados de ideologias e valores, nem sempre percebidos, mas revelados nas práticas e nos discursos. O texto foca essa questão, ressaltando as políticas que impactam a formação de professores no Brasil; reflete sobre os conceitos que incidem sobre o campo da formação docente; toma autores contemporâneos e os resultados de pesquisas para fundamentar os argumentos que apresenta.
\end{abstract}

Palavras-chave: Formação de professores. Cursos de licenciaturas. Políticas educacionais. Tendências na formação docente.

Intencionalmente, no decorrer deste escrito, assumimos a complexidade de separar as clássicas compreensões de formação como inicial e continuada. Justifica-se essa opção por entender que os movimentos políticos e epistemológicos que, de acordo com a história, marcaram a área da formação, atingiram as duas modalidades. Entretanto, dada a significação e a constituição de um espaço legal que traça os rumos da formação inicial, parece ser importante uma reflexão especial nesse tema.

A formação inicial' de professores tem sido objeto de estudos e exige análises permanentes sobre sua configuração e sobre suas práticas, situadas historicamente no panorama das políticas públicas e nos processos de operacionalização dessas políticas. A formação e suas implicações de identidade não se constituem em um constructo arbitrário, mas decorrem

\footnotetext{
* Artigo recebido em 31/05/2012 e aprovado em 15/08/2012.
} 
de uma concepção de educação e de mundo que - mediada pelo trabalho com o conhecimento, como categoria fundante das relações pedagógicas, humanas e socioculturais - possibilita o ato educativo.

Os questionamentos sobre a formação, buscando suas finalidades eticoculturais e cidadãs, trazem inquietações para a produção de sentidos que permitam uma compreensão e uma intervenção possível nos processos formativos. Esses processos estão impregnados das ideologias e dos valores, nem sempre percebidos, mas revelados nos atos e nas escolhas realizadas.

A porosidade da palavra formação exige um cuidado para que não se caia em uma discussão que a banalize e se esvazie de sentido. É importante uma compreensão sobre o momento em que se vive, incluindo as reformas no campo educativo. A formação pode se configurar em múltiplas e diferentes dimensões, dependendo de onde se mira o objeto: a formação que se oferece, organizada exteriormente ao sujeito, ou a do ponto de vista do sujeito, entendida como a formação que se ativa como iniciativa pessoal (MARCELO GARCIA, 1992). De qualquer forma, nessas duas perspectivas, é possível perceber a importância dos processos de formação que o autor considera como uma das pedras angulares nos movimentos da educação. Compreendese a formação inicial como uma prática social com funções determinadas em termos de reprodução, de regulação e de manutenção do sistema vigente e que, ao mesmo tempo, se expressa com valores contraditórios e práticas controversas.

\section{As LICENCIATURAS: OS CENÁRIOS POLITICOS E DISPOSITIVOS LEGAIS NO BRASIL}

Retomando a história, no Brasil, as licenciaturas foram criadas com a chamada fórmula $3+1$, sendo os conhecimentos de natureza pedagógica trabalhados no último ano, após o desenvolvimento de disciplinas de conteúdo disciplinar do respectivo curso (Artes, Biologia, Educação Física, Física e das outras áreas de conhecimento em que são produzidas as disciplinas dos anos finais do ensino fundamental e do ensino médio). Ou seja, três (3) anos de formação dita específica e um (1) ano de formação pedagógica. Nesse modelo curricular, a responsabilidade de formar o professor se concentrava nas chamadas matérias pedagógicas, como: Didática, Psicologia, Sociologia e, em alguns casos, Filosofia e Antropologia. Em geral, assumiam-se alguns pressupostos básicos que envolviam o primado da teoria sobre a prática, quando os estudos teóricos vinham antes da prática e o estágio, no final do curso, era visto como um momento de aplicação da teoria na prática. Afastavase da concepção de ser uma experiência de aprendizagem e fortalecimento da construção da identidade profissional do trabalho docente. 
As Diretrizes Curriculares de 2001 e 2002, na tentativa de superação da proposta anterior, apresentaram currículos organizados de forma a privilegiar a tematização dos conhecimentos escolarizados, dos saberes da experiência e dos processos de iniciação científica. Também se propôs a inserção no campo profissional desde o início da formação, incluindo o estágio curricular supervisionado a partir da metade do curso, como fortalecimento da identidade do curso de licenciatura, sem ser um apêndice do bacharelado.

As Diretrizes representaram um processo rupturante com o chamado modelo 3+1, tal como afirma Ghedin (2008), pontuando avanços sobre o modelo anterior: a licenciatura ganhou especificidade e integralidade própria em relação ao bacharelado, constituindo-se em um objeto específico; a licenciatura passou a ter definição de currículo próprio, sem confundir-se com o bacharelado ou com o antigo "modelo $3+1$ ".

A proposta legal favoreceu que a formação de professores possa a ser realizada em um processo mais autônomo, tratando-se de um curso com identidade própria.

Entretanto algumas críticas vêm acompanhando essa proposta. Dentre as mais acirradas, destacam-se as que denunciam o esvaziamento da responsabilidade acadêmica com a formação e, como consequência, um risco de desprofissionalização dos professores, pois a indissociabilidade entre ensino, pesquisa e extensão, que caracteriza a universidade, ficaria comprometida. Ao afastar-se da proposta que privilegia a teoria sobre a prática, corre-se o risco de retirar a reflexão crítica dos processos de formação de professores, podendo ocorrer sua desintelectualização. As intencionalidades do projeto, nas palavras de Moraes (2003), podem representar um recuo da teoria. A autora expressa a preocupação de que, com frequência, a discussão teórica seja gradativamente suprimida ou relegada a um segundo plano, havendo o risco de uma banalização dos modos de produção de conhecimento nesse campo e, também, em outras áreas, no decurso do tempo.

Moraes ainda aponta que essa marcha à ré intelectual e teórica (MORAES, 2003, p.154) talvez esteja presente na definição e efetivação das próprias políticas educacionais, em nível nacional e internacional. Apresenta a ideia de que esse recuo da teoria - algumas vezes considerado até retrocesso poderá mostrar indícios da degradação teórica no campo educacional, através de um aspecto relevante ligado à ressignificação dos conceitos enunciados nos documentos oficiais. Há que se ter cuidado com o jogo de palavras, como também afirma Janela Afonso (2002), utilizando a ideia de ressemantização retórica. Dias-da-Silva (2005) também mantém a mesma linha de crítica às mudanças propostas pelas Diretrizes Curriculares. Ela se manifesta temerosa 
de que, semelhante ao processo de desinvestimento no conhecimento que vem rondando nossas escolas básicas, também, nos cursos de licenciatura, estejamos, em nome da valorização do cotidiano de escolas, dos saberes dos professores e suas "práticas", negligenciando o conhecimento educacional nos desenhos curriculares reformulados.

É possível concordar que a intencionalidade de alguns legisladores pode ter sido a de um aligeiramento dos processos formativos dentro da lógica de mercado. Por outro lado, percebe-se uma possibilidade maior de ocupar espaços de contradição nessas diretrizes, até pela ambiguidade de sua elaboração teórica. Ao analisar a duração dos cursos de licenciatura da maioria das instituições de ensino superior, verifica-se que, ao ser definido para eles o mínimo de $\mathbf{2 8 0 0}$ horas, essa duração significou uma condição máxima de três anos, o que é realmente um tempo restrito, especialmente em função da proposta de matriz ${ }^{2}$ curricular. Entretanto, essa condição criticável não pode ser motivo de uma suspeição generalizada que não reconheça alguns avanços trazidos pela legislação em vigor.

Muitos interrogantes remetem ao enfrentamento das dicotomias presentes na formação inicial, incluindo até antagonismos que abrangem as relações entre sujeito e objeto, teoria e prática, conteúdo e forma, consciência e matéria, subjetividade e objetividade. Considera-se que a inserção da prática como componente curricular, assumida nas atuais Diretrizes Curriculares, pode fortalecer a recriação da relação dialética entre teoria e prática que se corporifica também na relação conteúdo e forma.

É possível compreender, por meio da historicidade da história, que a relação teoria e prática se apresenta como um problema ainda não resolvido em nossa tradição filosófica, epistemológica e pedagógica. A teoria, vista na ótica da racionalidade técnica, traz como representação a ideia de que ela se comprovará na prática. Coloca-se em suspeição a perspectiva de que a teoria pode anteceder à prática. Assumem-se as soluções trazidas pela teoria em movimentos de padrões universais, descontextualizados com modelos que reduzem a complexidade do mundo da vida e do trabalho. Essa visão polarizada da teoria e da prática não dá conta dessa complexidade e da compreensão da instância epistêmica em que se produzem as teorias, que são recortes de realidade desse mundo. Realidade experimentada em uma relação intermutável de tempo e de espaço e produzida nas condições e possibilidades dos processos histórico-culturais de cada tempo e de cada espaço, ou melhor, dizendo de cada espaço-tempo.

Nesse sentido, há uma urgência de uma postura tencionada entre elas, entendendo que a teoria, dialeticamente, está imbricada com a prática. 
Caso contrário, a teoria tende a se tornar um acúmulo de informações sem uma sistematização que fundamente as evidências colhidas em uma prática refletida que a projete e recrie. Essa relação - dialetizada nas contradições e imprevisibilidades que a realidade complexa, mutante e ambivalente possibilita - faz com que "na prática a teoria seja outra", exigindo que se mude a teoria para se transformar em prática. O desafio é tomá-las como totalidade, como faces indissociáveis do ato de conhecer.

A cisão entre sujeito e objeto, que tem nos coisificado, se reproduz na cisão teoria e prática, como se fora possível construir uma teoria sem que ela tenha passado pelo filtro da prática refletida em seu locus sociocultural, ou de uma prática sem reflexão, sem ter um cerne teórico, mesmo que não claramente explicitado. O risco de uma teoria geral sem embate com a prática, e esta reduzida a uma ação repetida sem questionamentos, não só dicotomiza o ato de conhecer, como aliena os sujeitos de seus objetos de estudo para compreensões mais elaboradas e transformadoras. Não se está a defender o praticismo, mas, sim, uma epistemologia da prática que traga a reflexão como um processo dialético e contextualizado nas condições objetivas do mundo da vida e do trabalho. Entretanto, há que se ter um cuidado epistemológico, como alerta Zeichner (1995), pois há o perigo de tratar a reflexão como um fim em si, sem ter nada a ver com objetivos mais amplos. A reflexão pode, em certos casos, solidificar e justificar práticas de ensino prejudiciais para os alunos e minar ligações importantes entre a escola e a comunidade. Por vezes, os professores reflexivos podem fazer coisas prejudiciais, melhor e com mais justificações.

São dilemas que se configuram para a formação inicial, anunciando alguns avanços e constantes desafios. Ao mesmo tempo que pode haver um aligeiramento da formação pelo encurtamento do tempo de formação, pode, também, haver avanços no sentido de superação do distanciamento das práticas sociais em que são produzidos os saberes docentes, incluindo maior conhecimento da realidade da escola. São possibilidades concretas que ocorrem através da inserção do professor em formação no campo profissional, já no início do percurso curricular, superando características do modelo da racionalidade técnica. Cabe à universidade assumir a complexidade dessa formação e a consequente responsabilidade, enquanto campo da formação e da atuação desse profissional como um projeto institucional, e não como uma espécie de tarifa que ela paga para poder fazer ciência em paz (MENEZES, 1986).

É certo que nem a história nem as instituições são lineares, mas se constituem como espaços de contradição. São produzidas e se produzem no movimento da vida cotidiana, o que pode favorecer rupturas e continuidades, 
bem como construírem uma consistente epistemologia da prática. Talvez seja necessário enfatizar mais a leitura do campo disciplinar e do cotidiano como uma categoria de conteúdo para uma possibilidade de reinvenção de processos críticos de formação de professores. Depoimentos ${ }^{3}$ de professores em formação que afirmam que é preciso trabalhar mais com a prática na prática, estendendo o curso para que os alunos trabalhadores possam fazer realmente uma boa prática e um bom estágio, sinalizam essa reinvenção (FERNANDES, 2008).

Para dar conta da ocupação de espaços contraditórios e das controvérsias nas reformas das licenciaturas, ${ }^{4}$ apoiamo-nos na afirmativa de Vieira Pinto:

O pensamento dialético nos ensina que existe de fato negação de um conhecimento velho por um novo, mas não se trata de mera substituição, de remoção de um e colocação de outro no mesmo lugar, pois o velho persiste como parte componente da constituição do novo, que provém daquele e, embora o negando, conserva-o sob outro aspecto. (VIEIRA PINTO, 1969, p. 284)

Nessa perspectiva, percebe-se que há maior visibilidade e possibilidade de ocupar espaços de contradição. Envolveria uma questão de tempo e de comprometimento pessoal e institucional, mas o caminho está em aberto. Não se trata de fazer terra arrasada, mas, sim, de desconstruir e reconstruir o novo de novo (GRAMSCI, 1982). E que a importância da formação de professores saia da retórica e realmente se institua como uma das prioridades da universidade (DINIZ PEREIRA, 2008).

As discussões sobre a formação inicial de professores, como aqui explicitada, reafirmam que a formação não é um campo neutro e que está fortemente imbricada nas dimensões políticas e epistemológicas de seu tempo. Compreender os conceitos contemporâneos ajuda a ter melhores condições de intervenção nesse campo de produção de conhecimentos e de práticas com sentido social.

\section{A FORMAÇÃO INICIAL DE PROFESSORES ENTRE OS CONCEITOS CONTEMPORÂNEOS}

Em contradição à perspectiva de redução da docência a um neotecnicismo integrante das políticas neoliberais, uma crescente energia foi mobilizada em estudos baseados nas narrativas culturais e de desenvolvimento profissional. Nelas, compreende-se que o professor age a partir de saberes que são plurais e construídos por diferentes fontes. Constrói seus saberes com raiz em múltiplas influências de formação, em cotejamento com o con- 
texto cultural e institucional em que atua. As contribuições de Nóvoa (1997), Charlot (2000), Alarcão (1996), Tardif (2002), Gauthier (1999) e Marcelo Garcia (1999), no plano internacional, foram de grande impacto no Brasil, produzindo diálogos profícuos com Pimenta (1999), Ramalho (2004) Cunha (2006) e tantos pesquisadores dos saberes docentes, instalados no âmbito acadêmico. Tudo indica que a força do termo "saberes" se institui em contraponto com a denominação das "competências", em uma expressa intenção de resistir à redução da complexidade da docência e de sua formação.

Tomando o referencial de Tardif $(2001,2002)$ e Tardif e Raymond (2000) para analisar os saberes que constituem a profissão docente, percebe-se que há fontes diversas que inspiram as escolhas dos professores para configurar o cotidiano de seu trabalho. Os autores afirmam que os saberes da docência são plurais e heterogêneos, portanto, oriundos de diferentes fontes e processos. Entre eles, citam a história cultural dos sujeitos na escola como uma inspiração de grande importância. Essa perspectiva se aproxima do conceito de cultura experiencial de Perez Gomes (1998). Para esse autor, a cultura experiencial trata da peculiar configuração de significados e comportamentos que os sujeitos elaboram de forma particular, induzidos pelo contexto, em sua vida prévia e paralela à escola, através dos intercâmbios com o meio familiar e social que rodeiam a sua existência, ainda que mediados por sua experiência biográfica e sua trajetória pessoal. A cultura experiencial de professores e estudantes serve de base principal para a construção da identidade institucional, afirma Perez Gomes. Outros estudos têm reforçado essa perspectiva (CUNHA, 1989; PIMENTA \& ANASTASIOU, 2002) e, sendo frutos de pesquisa, atestam o fato de os professores recorrerem às suas experiências como estudantes para tomar decisões sobre a forma como ensinam.

Recuperando a concepção epistemológica que assume a subjetividade e a experiência como fonte insubstituível de aprendizagem, Tardif (2002) dá especial relevo, também, às aprendizagens que o professor realiza no ambiente de trabalho, a partir da sua inserção profissional. O autor analisa ainda a relação entre o trabalho do professor e seu objeto de trabalho que é, fundamentalmente, o aluno, tanto na sua dimensão individual como grupal, e o processo ensino-aprendizagem. Dada essa condição, as relações que o professor estabelece com seu trabalho são de natureza humana, sujeitas às interferências valorativas e construídas em um contexto de complexibilidade. Nesse sentido, é inadequado pensar que o professor tem controle direto sobre seu objeto de trabalho, como acontece em outros campos profissionais. "Nada nem ninguém pode forçar um aluno a aprender se ele mesmo não se empenhar no processo de aprendizagem [...], pois os alunos sofrem inúmeras influências que podem afetar seu rendimento escolar" (TARDIF, 2002, p. 132). 
Fazendo uma analogia com o trabalho industrial, Tardif (2002) ressalta que, para esse, há uma relação direta entre processo e produto; já na docência, o produto do ensino é de grande intangibilidade, pois diz respeito, principalmente, a atributos humanos e sociais que, por sua natureza, são de difícil mensuração.

Outra dimensão que pode afetar profundamente os saberes dos professores está ligada ao reforço da condição de visão única, tão cara à ciência moderna e, nos dias de hoje, reforçada pelos dispositivos políticos da produtividade. Trata-se de um processo de padronização, como se houvesse uma única forma de conhecimento e uma só alternativa de formação. Como lembra Sousa Santos, o dilema consiste em que a validação de uma só forma de conhecimento provoca a cegueira epistemológica e valorativa, destruindo as relações entre os objetos e, nessa trajetória, elimina as demais formas alternativas de conhecimentos. "O reverso da força da visão única é a incapacidade para reconhecer visões alternativas" (SOUSA SANTOS, 2000, p. 241). O autor, sabiamente, alerta que esse fenômeno pode redundar em um epistemicídio, afirmando que a "destruição de formas alternativas de conhecimento não é um artefato sem consequências, antes implica a destruição de práticas sociais e desqualificação de agentes sociais que operam de acordo com o conhecimento em causa" (p. 242).

Frente a esse quadro, é fácil perceber que os esforços que marcaram o início de uma ruptura epistemológica no campo da educação e da formação inicial de professores estiveram seriamente ameaçados. Ainda frágeis e minoritários, eles procuravam afirmar-se no campo acadêmico, com toda a dificuldade decorrente da presença paradigmática dominante. Sousa Santos (2000, p.344) afirma que "a luta paradigmática é, no seu conjunto, altamente arriscada", pois exige uma subjetividade emergente que envolve ruptura epistemológica e societal. Para o autor, formas alternativas de conhecimento geram práticas alternativas e vice-versa (p. 344), perpassando o conceito de subjetividade que se constitui como o grande mediador entre conhecimento e práticas. Certamente, são essas as tensões contemporâneas para a formação de professores e todos os movimentos e alternativas revelarão a complexidade que demandam.

\section{PRINCIPAIS FOCOS DE PESQUISA}

Quando se toma o pressuposto de que a pesquisa pode ser um elemento-chave para a formação emancipadora, está-se adotando a ideia de coerência entre os processos investigativos e uma proposição valorativa de educação. À medida que o paradigma da racionalidade técnica foi dando 
lugar à compreensão do fenômeno educativo como produzido social e culturalmente, houve significativas mudanças nas formas de produzir conhecimento sobre educação.

As pesquisas continuam abordando os temas clássicos da formação de professores, incluindo a formação inicial e continuada, os saberes em constituição na prática profissional e as condições de profissionalização. Reconhecer o espaço de trabalho como lugar de formação redundou em uma tendência significativa de pesquisar o docente em seu contexto de atuação, em que ele é reconhecido como produtor de saberes e, ao mesmo tempo, responde, enquanto produzido, às condições objetivas de existência e profissionalização. Nessa direção, os pressupostos investigativos que assumem a dimensão cultural têm sido recorrentes, porque melhor respondem às exigências epistemológicas.

Outra vertente exponencial no campo da formação de professores refere-se à incorporação das chamadas epistemologias da prática, que inseriram termos como professor reflexivo e professor investigador e que estimularam estudos sobre o"professor aprendente", em uma clara intenção de pesquisar o professor como sujeito epistêmico que vai reconfigurando seus saberes em função dos desafios profissionais que a prática lhe impõe.

É possível discutir a ideia de uma epistemologia da prática que não se identifique com um praticismo inconsequente, facilmente criticado pela possibilidade de constituir-se afastado da teoria. Nessa perspectiva, os processos de formação docente estariam se fragilizando através do aligeiramento das propostas curriculares. No atual contexto, em que as políticas globalizadoras e economicistas pressionam para uma formação rápida e de massas, essa é uma ameaça significativa. Entretanto esse argumento não tem servido para anular a importância de teorias que tomam a epistemologia da prática como eixo articulador da formação. De forma especial, porque foram constantes as denúncias da fragilidade do modelo de formação em que se propunha uma teorização desconectada da prática e do cotidiano dos docentes e alunos.

O campo da formação de professores, atingido pelas mudanças paradigmáticas, assumiu, quase com exclusividade, a pesquisa qualitativa como forma de produção de conhecimento. A compreensão de qualidade - como "propriedade, atributo ou condição das coisas ou pessoas, capaz de distingui-las de outras e de lhes determinar a natureza" (FERREIRA, 1986, p. 1425) - favoreceu a ruptura epistemológica desejada e fomentou estudos que se distanciavam da neutralidade e das universais generalizações. Essa posição estimulou a presença de correntes teóricas vindas da fenomenologia, da etnografia e da dialética no campo da pesquisa educacional. Ao mesmo 
tempo, instalava-se um impulso de mudança nas práticas pedagógicas, a partir das compreensões que anulavam a relação de poder entre sujeito e objeto, e advogavam-se os processos participativos de pesquisa e resolução dos problemas educacionais. A pesquisa-ação e a pesquisa-participante foram assumindo papel relevante no cenário educacional. Procurava-se, em todas essas vertentes, estudar o professor como um sujeito histórico e culturalmente situado e sua formação como decorrente das múltiplas fontes e energias mobilizadas para tal.

Ao invés de instituir categorias teóricas a priori, instalaram-se movimentos investigativos que tentavam construí-las a partir do fenômeno pesquisado, aprofundando a complexidade dos fatos sociais nas suas relações e interdependências, dando um destaque aos saberes dos sujeitos em seu cotidiano.

Para estudar os saberes, a ampliação do uso das narrativas tornouse usual e recomendável, uma vez que essas são compreendidas a partir de uma produção cultural e histórica, o que reforça a posição de Larrosa (2004, p. 19), para quem a "história de nossas vidas depende do conjunto de histórias que ouvimos, em relação às quais, temos aprendido a construir as nossas". A profissão docente, sendo profundamente enraizada na prática cultural dos professores, exige uma reflexão narrativa intensa, para que sejam exploradas as representações sociais que as sustentam.

A incorporação das narrativas como valor provocou uma reconfiguração da relação teoria e prática, pois esta cada vez mais se distancia da concepção instrumental aplicacionista, e se institui como um eixo fundamental para pensar a profissão docente.

FORMAÇÃO DE PROFESSORES: TENDÊNCIAS, PROPOSIÇÕES E DILEMAS

Todas as fases que marcam as tendências dos estudos sobre a formação de professores produziram conceitos e se apresentaram como produtos e produtoras das ações formativas, influenciando e sendo influenciadas pelas políticas, legislações e culturas.

A temática da formação de professores se coloca como um tema inesgotável e é sempre instigadora da educação superior. Provocou e vem provocando diferentes abordagens de estudo e exigindo desdobramentos na sua análise e compreensão. As exigências da profissionalização reabriram as reflexões específicas sobre a formação continuada dos docentes de todos os níveis e essas provocaram a necessidade de repensar a formação inicial. Ambas continuam exigindo esforços e estimulando o espírito investigativo da base acadêmica. Parece que a necessidade de estudar o professor e sua 
formação é tão permanente quanto inexorável é a ideia de processo na sua condição humana, em sua organização social. As mudanças na sociedade definirão sempre novas abordagens para a educação dos homens e, como decorrência, diferentes aportes no papel e formação de professores, o que se coloca como um permanente desafio para a pesquisa e para a universidade.

No que tange à formação inicial, a exigência de uma epistemologia da prática, construída em bases sólidas pela reflexão teórica, necessita de um tempo, cronos de maturação, para uma inserção orientada no campo profissional, o que demanda um currículo com espaços para uma efetiva prática como componente curricular. Exige uma disposição acadêmica intensa e continuadamente refletida, que extrapola inserções pontuais na prática, durante o percurso curricular. É preciso fortalecer o sentimento de pertença dos estudantes, enfatizando o significado da presença nas atividades a serem realizadas pelos professores em formação no percurso do curso de Formação de Professores. Articulando a formação com a pesquisa, o sentido do Trabalho de Conclusão de Curso (TCC), nos cursos de licenciaturas, precisaria expressar a tessitura realizada pelos estudantes, o que inclui a territorialização do estágio e a articulação com as temáticas de construção pedagógica do conhecimento do seu campo disciplinar. Para a universidade, o desafio que se impõe é a articulação dos lugares de formação, enfrentando a dicotomia estrutural que secciona os currículos e a base de articulação dos docentes em territórios distintos. Como afirma Saviani:

Parece que na raiz desse mal-estar está a dissociação entre dois aspectos essenciais do ato educativo e, portanto, da função docente: a forma e o conteúdo. Tal dissociação é processada pelo modo como estão construídas as especializações universitárias e para sair desse dilema é preciso recuperar os saberes que constituem, de parte a parte, a desejada indissociabilidade. (SAVIANI, 1998, P.140)

Para o autor a alternativa seria considerar $\mathrm{o}$ ato docente enquanto fenômeno concreto, isso é, tal como ele se dá no interior da escola. Dessa forma, a relação conteúdo-forma se nutre da relação teoria-prática e a articulação desses dois eixos se torna o grande e permanente desafio da formação, incluindo aspectos epistemológicos, pedagógicos e políticos.

Nessa direção algumas alternativas podem ser propostas:

- consolidar na universidade o campo epistemológico da educação, incluindo a pesquisa como elemento chave desse processo;

- reconhecer o conhecimento pedagógico como legítimo, o que pressupõe seu reconhecimento também para a docência 
universitária, pois essa é condição para assumir a legitimidade desse saber para todos os professores;

- assumir politicamente a formação de professores para todos os níveis como tarefa acadêmica, implementando formatos organizacionais que superem a dualidade forma-conteúdo;

- exercitar uma base epistemológica que articule: teoria e prática/ ensino; e pesquisa, ensino/aprendizagem;

- assumir a docência como ação complexa que exige, para a sua formação, uma base comum e articulada, envolvendo a universidade, a escola e o aluno aprendente;

- investir na legitimação dos espaços de trabalho como lugar de formação.

É certo que são desafios potentes. Mas é preciso ultrapassar os diagnósticos e colocar em prática alternativas que correspondam aos estudos já realizados. Essa é a responsabilidade da universidade para com a formação de professores.

TEACHER FORMATION: TENSION BETWEEN DISCOURSE, POLICY, THEORY AND PRACTICE

ABSTRACT: Questions about teacher formation cause concern for the production of meanings which allows for an understanding and an intervention in formative processes. These processes are impregnated with ideologies and values, which are not always noticed, but manifest themselves in practice and in discourse. The text provides an analysis of the policies which have influenced initial teacher formation in Brazil and it also contributes to a reflection on the concepts which affect the field of teacher formation. Contemporary authors and the results of research are used to substantiate the arguments presented in the text.

Keywords: Teacher formation. Licentiate courses. Educational policies. Trends in teacher formation.

FORMACIÓN DE PROFESORES: TENSIÓN ENTRE DISCURSOS, POLÍTICAS, TEORÍAS Y PRÁCTICAS

RESUMEN: Los cuestionamientos sobre la formación de profesores generan inquietudes para la producción de sentidos que permitan una compreensión e intervención en los procesos formativos. Son procesos impregnados de ideologías y valores, no siempre percibidos, pero revelados en las prácticas y en los discursos. El texto focaliza este tema, resaltando las políticas que impactan la formación de profesores en el Brasil, y haciendo reflexionar sobrelos conceptos que tienen incidencia en el campo de la 
formación docente. Toma autores contemporáneos y los resultados de investigaciones para cimentar los argumentos que presenta.

PalABRAs CLAVEs: Formación de profesores. Cursos de licenciaturas. Políticas educacionales Tendencias en la formación docente.

\section{NOTAS}

1. O sentido inicial na formação de professores trata dos cursos de licenciatura que habilitam e legitimam o exercício da docência na escola básica.

2.400 (quatrocentas) horas de prática como componente curricular, 400 (quatrocentas) horas de estágio curricular supervisionado de ensino, além de 200 (duzentas) horas de outras formas de atividades acadêmico-culturais, além das $1800 \mathrm{~h}$ (mil e oitocentas) horas de aulas para os conteúdos curriculares de natureza científico-cultural.

3. Fala síntese de interlocutores da pesquisa -"A constituição do campo de saberes do professor em formação: o desafio da articulação teoria-prática e as tensões do campo da formação e do campo profissional".

4. Especialmente as mudanças trazidas com as Resoluções 01 e 02/2002 e o Parecer 09/2001 do Conselho Nacional de Educação/Conselho Pleno, dentre outros pareceres/ resoluções que inundaram a década de 90 .

\section{REFERÊNCIAS}

ALARCÃO, I. Formação reflexiva de professores. Estratégias de supervisão. Porto: Porto Editora, 1996.

CHARLOT, B. Da relação com o saber: elementos para uma teoria. Porto Alegre: Artmed, 2000.

CUNHA, M. I. da. O bom professor e sua prática. Campinas: Papirus, 1989.

CUNHA, M. I. da. A formação de professores como problema: natureza, temporalidade e cultura. Cadernos de Educação, Pelotas, FaE/UFPel, n. 27, p. 55-71, jul./dez. 2006.

DIAS-DA-SILVA, M. H. G. F. Política de formação de professores no Brasil: as ciladas da reestruturação das licenciaturas. Revista Perspectiva, Florianópolis, v. 23, n. 02, p. 381 406, jul./dez. 2005. Disponível em: www.ced.ufsc.br/núcleos/nup/perspectiva.html. Acesso em: 19 mar. 2006.

DINIZ PEREIRA, J. E. A prática enquanto componente curricular e a formação docente. Palestra no V CICLO DE ESTUDOS DE LINGUAGEM. Ponta Grossa, PA: Universidade Estadual de Ponta Grossa, 2008.

FERNANDES, C. M. O espaço-tempo do estágio nos movimentos do curso: interrogantes, desafios e construção de territorialidades. In: EGGERT, E.; TRAVERSINI, C.; PERES, E.; BONIN, I. (Org.). Trajetórias e processos de ensinar e aprender: práticas e didáticas. Porto Alegre: XIV ENDIPE. EDIPUCRS, 2008. p. 231-248. 
FERREIRA, A. B. de H. Novo dicionário da língua portuguesa. Rio de Janeiro: Nova Fronteira, 1986.

GAUTHIER, J. O que é pesquisar - Entre Deleuze e Guattari e o candomblé. Pensando mito, ciência, arte e culturas de resistência. Educação e Sociedade, ano XX, n. 69, p. 13-33, dez. 1999.

GHEDIN, E. et al. Formação de professores. Caminhos e descaminhos da prática. Brasília: Líber Livro Editora, 2008.

GRAMSCI, A. Os intelectuais e a organização da cultura. 4. ed. Rio de Janeiro: Civilização Brasileira, 1982.

JANELA AFONSO, A. Palestra no PROGRAMA DE PÓS-GRADUAÇÃO DA UNIVERSIDADE DO VALE DO RIO DOS SINOS. São Leopoldo: 2002.

LAROSSA, J. Notas sobre narrativa e identidade. In: ABRHÃO, M. H. A aventura (auto) biográfica. Porto Alegre: EDIPUCRS, 2004. p.11-23.

MARCELO GARCIA, C. Formação de professores. Porto: Porto Editora, 1999.

MARCELO GARCIA, C. A formação de professores: novas perspectivas baseadas na investigação sobre o pensamento do professor. In: NÓVOA, A. (Coord.). Os professores e sua formação. Lisboa: Dom Quixote, 1992. p. 51-76.

MENEZES, L. C. de. Formar professores: tarefa da universidade. In: CATANI, D. B. et al. (Org.). Universidade, escola e formação de professores. São Paulo: Brasiliense, 1986. p. 115-125.

MORAES, M. C. M. (Org). Iluminismo às avessas. Produção de conhecimento e políticas de formação docente. Rio de Janeiro: DP\&A Editora, 2003.

NOVOA, A. (Coord.). Os professores e sua formação. 3. ed. Portugal: Dom Quixote. 1997. PEREZ GOMEZ, A. I. La cultura escolar en la sociedad neoliberal. Madri: Morata, 1998.

PIMENTA, S. G.; ANASTASIOU, L. Docência no ensino superior. São Paulo: Cortez, 2002. PIMENTA, S. G. (Org.). Saberes pedagógicos e atividade docente. São Paulo: Cortez, 1999. RAMALHO, B. Formar o professor, profissionalizar o ensino: perspectivas e desafios. 2 ed. Porto Alegre: Sulina, 2004.

RESOLUÇÃO DO CONSELHO NACIONAL DE EDUCAÇÃO - CONSELHO PLENO Resolução CNE/CP 2 de 19 de fevereiro de 2002. Diário Oficial da União, Brasília, 4 de março de 2002. Seção 1, p. 9.

RESOLUÇÃO DO CONSELHO NACIONAL DE EDUCAÇÃO - CONSELHO PLENO Resolução CNE/CP 1, de 18 de fevereiro de 2002. Diário Oficial da União, Brasília, 9 de abril de 2002. Seção 1, p. 31.

SAVIANI, D. O problema da formação de professores na Itália. In: GOREGEN, P.; SAVIANI, D. (Org.). Formação de professores. São Paulo: Autores Associados/NUPES, 1998. p. 115-157. 
SOUSA SANTOS, B. de. A crítica da razão indolente. Contra o desperdício da experiência. São Paulo: Cortez, 2000.

TARDIF, M. Saberes docentes e formação profissional. Petrópolis: Vozes, 2002.

TARDIF, M.O trabalho docente, a pedagogia e o ensino: interações humanas, tecnologia e dilemas. Cadernos de Educação, Faculdade de Educação da UFPel, ano 10, n.16, p. 7-14, jan./jun. 2001.

TARDIF, M.; RAYMOND, D. Saberes, tempo e aprendizagem do trabalho no magistério. Educação e Sociedade, ano XXI, n. 73, p. 33-48, dez. 2000.

VIEIRA PINTO, A. Ciência e existência. Rio de Janeiro: Paz e Terra, 1969.

ZEICHNER, K. Los profesores como profesionales reflexivos y la democratizacion de la reforma escolar. CONGRESO INTERNACIONAL DE DIDÁCTICA. Volver pensar la educación. v. 1. Madri: Ediciones Morata, 1995.

CLEONI MARIA BARBOZA FERNANDES é doutora em Educação pela UFRGS; professora do Programa de Pós-graduação em Educação da PUCRS; pesquisadora do Grupo de Pesquisa Formação de Professores, licenciaturas e práticas pedagógicas e do Centro de Estudos de Educação Superior - CEEES; integrante da Rede Sulbrasileira de Investigadores em Educação - RIES; bolsista do CNPq - Brasil.

E-mail: cleoni.fernandes@pucrs.br

MARIA ISABEL DA CUNHA é doutora em Educação pela Universidade Estadual de Campinas; professora aposentada da Faculdade de Educação da Universidade Federal de Pelotas (RS); docente titular do Programa de Pós-Graduação em Educação da Universidade do Vale do Rio dos Sinos (RS); pesquisadora da área de Educação, com ênfase em Educação Superior, atuando principalmente nos seguintes temas: formação de professores, pedagogia universitária e avaliação institucional. 